\title{
Climate Variability and Rice Production in North India: A Review
}

\author{
Surendra Singh* and Mohamad Awais
}

ICAR-National Institute of Agricultural Economics and Policy Research, Pusa, New Delhi, India

*Corresponding author: surendra.singh735@gmail.com

\begin{abstract}
Variability in climatic factors is one of the main determinants of agriculture production. Past agrarian studies have shown that variability in rainfall and temperature has decline agriculture production in entire North Indian States. Farmers, especially small and marginal are adversely affected from climate variability. They have less resources and coping strategies against the climatic variability. Rice is the one of important crop for all North Indian State's people. Level of temperature already reaches to tolerance level of crops and it is increasing day by day. Also variability in rainfall during Kharif cropping season has been reported in all North Indian states. Incidence of extreme climatic events such as drought and flood is also repeated in these areas. Level of carbon dioxide is also increased due to over exploitation of natural resources and industrial activities in these states. Growth in population is much higher in last three decades. So burden on natural resources such as on agriculture is becoming very high. Agriculture sector needs immediate action against climate variability. Mitigation strategies are time taking process. However, an adaptation method is best technique to mitigate consequences of climate variability. Sowing date and use of technological tools are the best adaptive method to minimize the impact of climate variability.
\end{abstract}

\section{Highlights}

( Climate change is adversely affecting to the agriculture and posing serious threat to livelihood security in North India. Among the Kharif season crops, rice crop was found highly climate sensitive.

Keywords: Carbon dioxide, rainfall, rice production, temperature, vulnerability

Climate is one of the main determinant factors of agricultural production. Throughout the world there is significant concern about the effect of climate change and its variability on agriculture production. Researchers are concerned with the potential damages of climate change that rises in agriculture. Past studies have shown a significant effect of changes in climatic factors on average crop yield (Mall et al. 2006; Cline, 2007; Seo and Mendelsohn 2008). Small farmers are most sensitive from climate variability as compared to large and commercial farmers with least adaptive capacity and higher reliance on the most vulnerable occupation like agriculture.

In India, past studies have shown that India is likely to witness one of the highest agricultural productivity losses in the world in accordance with the climate change pattern observed and scenarios projected (Kavi Kumar, 2010; Dash et al. 2007; Sathaye et al. 2006; Goswami et al. 2006; Srinivasan 2008). First, temperatures would be increase up to $2-4^{\circ} \mathrm{C}$ by 2100 with no substantial change in annual precipitation (Kavi kumar, 2010). Second, among the food crops, rice and wheat are the most climate sensitive crops and adversely affected to changing climate. Third, dry areas will get drier and the wet areas will get wetter. Fourth, there is also greater consensus now in future climate variability in India that will increase leading to more frequent extremes of weather in the form of uncertain onsets of monsoons and frequency and intensity of drought and flooding etc.

With these evidences, the present study has reviewed the existing literature on the nexus of 
climate change and rice production. Data of rainfall and temperatures during 1901-2010 have been analyzed to examine the variability in rainfall and temperature. Further, long average temperature and rainfall data have linked with previous studies to validate the thesis of climate change in the North Indian agricultural system. Lastly, mitigation and adaptation strategies have also been reviewed to overcome the current environmental crisis.

\section{Sensitivity to Southwest Monsoon: The Nexus Between Rainfall and Water}

The geographical position of India makes it highly vulnerable to different kinds of natural disasters. Figure 1 depicts annual variability in rainfall over North India. In the year 1997 and 1998 there was surplus rainfall. However, from 1999 to 2002, it shows negative trends over the North Indian states. Overall rainfall deficiency for the Northern States was 26.1 percent. Similar trend was shown in all over India. In 2002, water storage in 71 major reservoirs was 33 percent which is less than the average of previous 10 years. About 21.5 million ha area was not sown and 47 million hectare of sown area was damaged, with a food grain short fall of more than 29 million tons (GoI, 2003). About 300 million people were affected. A loss of 1250 million man-days of employment was also reported. Ground water table in entire North Indian states had declined by 2 to 4 meter below from normal levels. Every day about 1.5 billion liters of drinking water was transported by tankers and railways during drought period (GoI, 2003). Similar episode was repeated in the year 2004. In this year, 21.3 percent less rainfall has received in the North Indian States. Moreover, turning point comes in rainfall history of North Indian states in the year 2009. Entire north Indian states received -35.5 percent less rainfalls from normal rainfall level and suffered from drought.

\section{Maximum Temperature and Agriculture: Exploring the Nexus}

Temperature plays a vital role in agriculture production. Suitable temperature brought higher production. The present study has examined the changes in maximum temperature during 19012010 (Fig. 2). The mean maximum temperature has increased by $0.21{ }^{\circ} \mathrm{C}$ during 1901-50. The overall

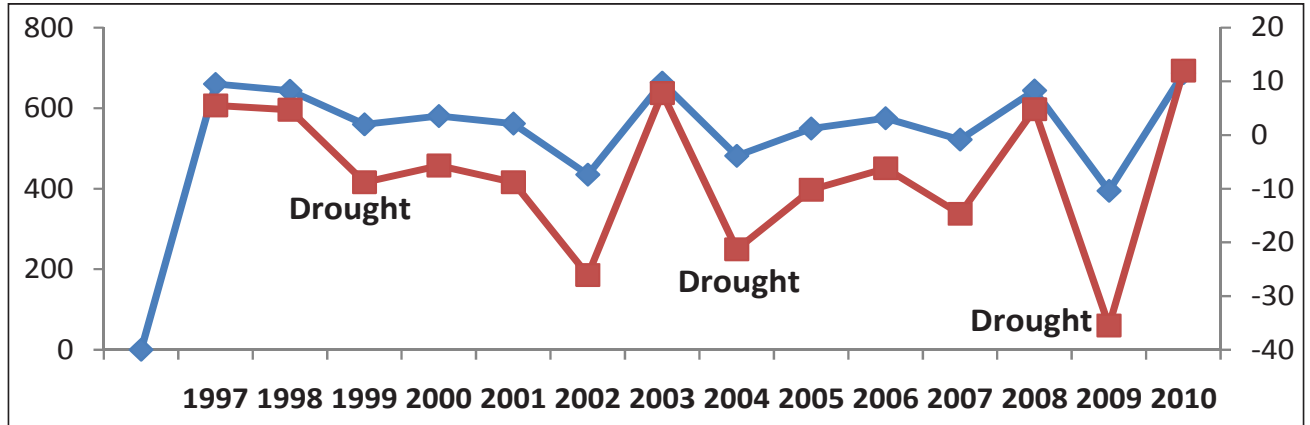

Fig. 1: Actual Rainfall and Deficit rainfall in North India during June-September over 1997- 2010

Source: Indian Metrological Department, India

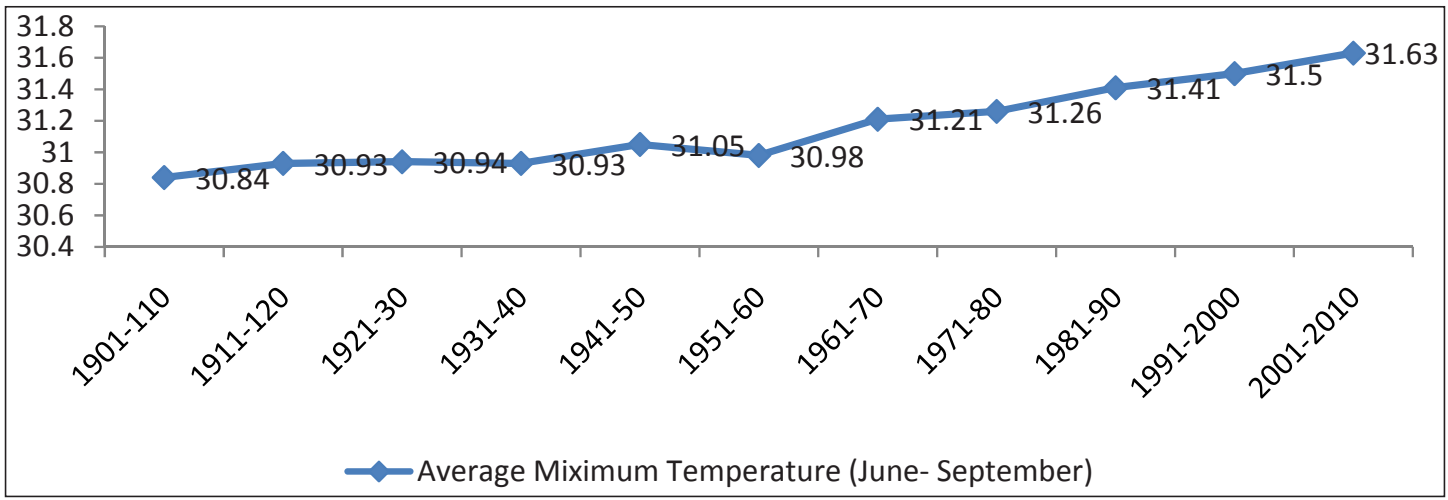

Fig. 2: Mean Maximum Temperature (June-September) all over India 1901-2010

Source: Indian Metrological Department, India 
increased in maximum temperature was reported by $0.79^{\circ} \mathrm{C}$ during 1901-2010. There are three key reasons for rapid increased in maximum temperature; (i) rapid industrialization and urbanization, (ii) change in land use pattern, and (iii) over-exploitation of natural resources.

Minimum temperature is also important in terms of agriculture production. Average minimum temperature in Northern India has shown increasing trend. In year 1901 average minimum temperature was $23.21{ }^{\circ} \mathrm{C}$ which is increase and in year 2010 reported as 23.45 (Fig. 3). Average minimum temperature has been increase as $0.24^{\circ} \mathrm{C}$. This temperature increased only for four month during rice season (Kharif crop season June to September month). As previously mentioned higher temperature poses negative trends in rice production. Sinha and Swaninathan (1991) estimate their studies that a $2^{\circ} \mathrm{C}$ increases in temperature could decreased rice yield by about 0.75 ton/ hectare in high-yield areas (Punjab, Haryana, and Uttar Pradesh) and by about 0.06 ton/ hectare in low-yield areas. Higher temperature either day or night affected growing period of rice yield. Higher temperature also brought physiological impacts on crops.

\section{Physiological Impacts on Crops}

Climate change has changed the physiology of crops in two manners; (i) exceed the rate of carbon fertilization, and (ii) speedup the rate of photosynthesis. For instance, the biomass yield of a crop can be taken as the product of the rate of biomass accumulation. The rate of biomass accumulation is determined by photosynthesis rate minus the respiration rate (biomass $=$ rate of photosynthesisrate of respiration). The first is primarily governed by the radiation and the latter by ambient air temperature. Higher temperature shortens the crop growth period; consequently reduce the period available to the plant for photosynthesis accumulation. Hence, highest potential yield of a particular annual crop is therefore obtained in regions where the crop duration is characterized by relatively low temperatures unless the radiation levels are also low (Ritchie, 1993). This is due to the fact that, at low temperature levels the crop gets more days to mature, therefore, accumulate more biomass. Hence, there will be a reduction in the grain weight of crop plants with increase temperature (Saseendran et al. 2000).

\section{Vulnerability from Climate Change in Agriculture}

In North India, agriculture purely depends on rivers for irrigation water. NATCOM-1(2004) has estimated that the severity of drought and intensity of floods are likely increase due to climatic variability. Ground water supplies are likely to be affected by a number of factors, including higher runoff leading to lower recharge increase in flooding in all over northern India. Scarcity of water in whole Gangatic belt also affected farmers in terms of ground water table. Basically rivers of Gangatic belt not only provided water for irrigation but also increased ground water table. Reports found that ground water table in these areas shown declined trends. When water table is decline farmers are digging bore wells more deeply for water, due to this activity, cost of agriculture inputs is increases day by day. Usually small and

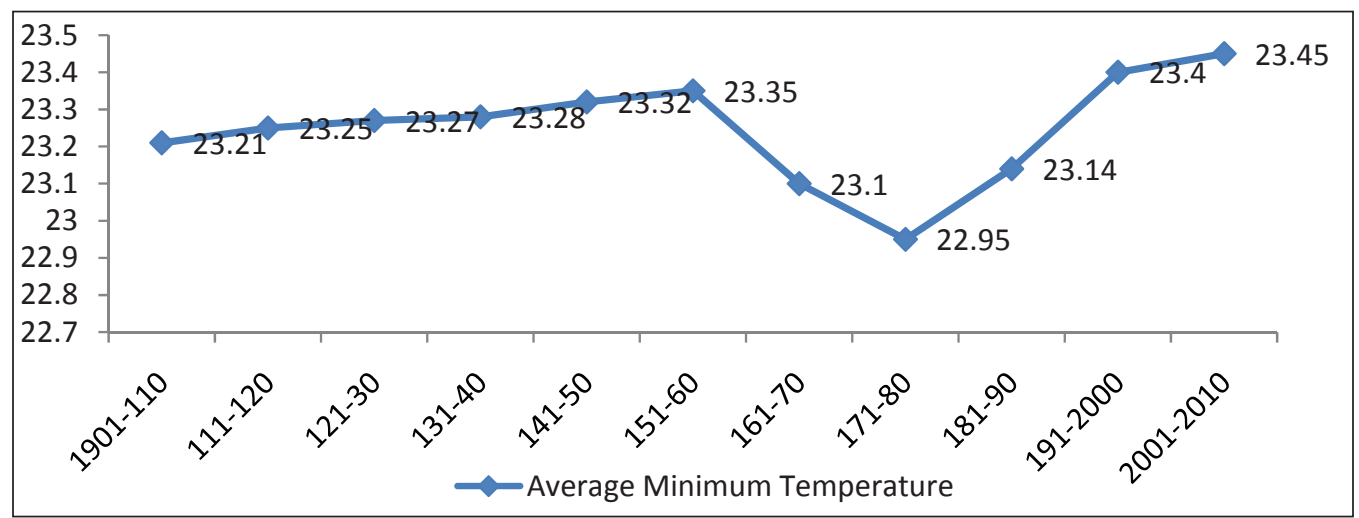

Fig. 3: Mean Maximum Temperature (June-September) all over India 1901-2010

Source: Indian Metrological Department, India 
marginal farmers are purchasing water for irrigation from state government or large farmers. When they have purchase water for irrigation from different bodies either government or private, it increased the input cost of agriculture. However, in many times water is not timely provided by these bodies which resulted complete or partial crop failure.

\section{Mitigation and Adaptation Strategies}

The purpose of mitigation and adaptation strategies is therefore to attempt a gradual reversal of the effects caused by climate change and sustain development under the inescapable effects of climate change. It is important to understand the subtle difference between mitigation and adaptation. Mitigation and adaptation are related to the temporal and spatial scales on which they are effective. The benefits of mitigation activities carried out today will be evidenced in several decades because of the long residence time of green house gases in the atmosphere, whereas the effects of adaptation measures should be apparent immediately or in the near future (Kumar and Parikh, 2001). Besides, mitigation strategies have global in adaptation to local benefits, whereas adaptation typically takes place on a local or regional scale.

Variability in rainfall affects agriculture productivity significantly and leads to stagnation decline in production across various agro-climatic zones. To mitigate the climate change considered changing cropping calendars and patterns will be the immediate best available option with available crop varieties. The option like introducing new cropping sequences, late or early maturing crop varieties depending on the available growing season, conserving soil moisture through appropriate tillage practices, efficient water harvesting techniques, and developing heat and drought tolerance crop varieties by utilizing genetic resources. That may be better adapted to new climatic and atmospheric conditions should be the long term strategy. Genetic manipulation may also help to exploit the beneficial effects of increased carbon dioxide on crop growth and water use. One of the promising approaches would be gene pyramiding to enhance the adaptation capacity of plants to climate change inputs.

\section{Sowing Date}

The effect of changing sowing date on the yield of rice was significant in several locations (Krishnan et al. 2007). These insights can be used to predict the effect of changing sowing dates with different future climate scenarios. For instance, changes to rice yield (Variety, IR36) under three global circulation models (GCMs), GFDL, GISS, UKMO are presented five sowing dates in Jorhat, India. Changes to sowing dates may necessitate other management adjustment as well. Table 1 represents impact of sowing dates on crop production. When crop is grow in the field at first June with all varieties of rice crops sowing negative trends. However, 15 June date of sowing positive trends. Another positive trend has shown when rice crop is sowing at first July. It shows that 27.1 percent more rice production. This table also describes importance of sowing date. However, when crop is sowing on first august with all type varieties sowing negative trends.

Table 1: Change in rice yield percent across future climate scenario under various sowing dates

\begin{tabular}{cccccc}
\hline Model & \multicolumn{5}{c}{ Sowing dates } \\
\hline GCM & $\mathbf{1}^{\text {st }}$ June & $\mathbf{1 5}^{\text {th }}$ June & $\mathbf{1}^{\text {st }} \mathbf{J u l y}$ & $\mathbf{1 5}^{\text {th }}$ July & $\mathbf{1}^{\text {st }}$ August \\
\hline GFDL & -9.4 & 13.5 & 27.1 & 17.2 & -6.8 \\
GISS & -8.6 & 12.3 & 24.3 & 16.8 & -7.5 \\
UKMO & -17.6 & 7.6 & 13.4 & 5.4 & -16.4 \\
\hline
\end{tabular}

Source: Krishnan et al. 2007.

\section{Breeding Strategies and Biotechnology}

Biotechnology may address at least several of the major stresses plants face from direct and indirect climate change impact (Cheikh et al. 2000) for example; salinity and drought tolerance to low temperatures has needed in rice, expanding its range. Crops could have developed drought or salinity tolerance and sub-freezing temperature. Less effort was put into developing genetic modification to allow heat tolerance in crops, mainly because heat stress was associated with drought, which has been widely addressed (IPCC, 2007b). A major task of our time is to ensure adequate food supplies for the world current population in a sustainable way while protecting the vital functions and biological diversity of global environment.

\section{CONCLUDING REMARKS}

Climate variability is disturbing agriculture practices all over the globe. Climate change has no boundary. 
It equally affected both developed and developing countries. India is second most populated country in the world, where the majority of rural population still dependent on agriculture for their livelihood and over 600 million farmers are involved in agriculture related activities or allied activities. It contributes about 30 percent of the gross domestic product in India. In India, number of small and marginal land holding is greater than compared to large and commercial land holdings. In many parts of India, especially in North Indian states farmers are cultivating crops by using traditional tools and techniques. For instance, farmers are not using genetically modified verities. In North Indian state, rise in temperature and variability in rainfall are adversely affecting to the agriculture and have making agriculture to climate sensitive.

Rice is a main food crops in North India that feeds millions of people and has a source of employment generation. In totality, climate change has brought livelihood and food crisis in North India. To anticipate this crisis, there is need of a comprehensive combat plan to deal with climate change. Inherent and planned adaptation strategies, i.e., change in cropping pattern, using modern biotechnology; shifting sowing dates and diversification in livelihood pattern are some of strategies to deal with climate change.

\section{REFERENCES}

Cline, William R. 2007. Global Warming and Agriculture: Impact Estimates by Country. Washington: Center for Global Development and Peterson Institute for International Economics.

Cheikh, N., P.W. Miller, G. Kishore. 2000. Role of Biotechnology in Crop Productivity in a Changing Environment. In: K.R. Reddy and H.F. Hodges, (eds.) Climate Change and Global Crop Productivity, Wallingford, Oxon, U.K.: CABI.

Dash, S.K., Jenamani, R.K., Kalsi, Panda, S.K. 2007. Some evidence of climate change in twentieth century India. Clim. Chan. 85: 299-32.

GoI 2003. Agricultural Statistics at a Glance. Ministry of Agriculture \& Farmers Welfare, Government of India, New Delhi.
Goswami, B.N., Venugopal, V., Sengupta, D., Madhusoodan, M.S. and Xavier, P. K. 2006. Increasing trend of extreme rain events over India in a warming environment. Science, 314: 1442-1445.

IPCC. 2007b. Climate Change 2007: Mitigation of Climate Change, Contribution of the Working Group III to the Fifth Assessment Report of the Intergovernmental Panel on Climate Change, Geneva, Switzerland.

Kumar, K.K.S. and Parikh, J. 2001. Socio- Economic Impacts of Climate Change on Indian Agriculture. Inter. Rev. Envir. Strat., 2(2): 12-15.

Krishnan, P., Swain, D.K., Chandra, B.B., Nayak, S.K. and Dash, R.N. 2007. Impact of elevated $\mathrm{CO}_{2}$ and temperature on rice yield and methods of adaptation as evaluated by crop simulation studies. Agric. Ecosyst. Environ., 122: 233-242.

Kavi Kumar, K.S. 2010. Climate sensitivity of Indian Agriculture: Role of Technological Development and Information Diffusion, In: Lead Papers National Symposium on Climate Change and Rainfed Agriculture, Indian Society of Dry land Agriculture, Central Research Institute for Dry land Agriculture, Hyderabad, 20: 1-18.

Mall, R.K., Ranjeet S., Akhilesh G., G., Srinivasan, S. Rathore 2006. Impact of climate change on Indian agriculture: A Review. Clim. Chan., 78: 445-478.

NATCOM-1. 2004. India's First Communication to United Nations, Government of India, New Delhi.

Ritchie, J.T. 1993. Genetic specific data for crop modeling. In: Pennig de Vries, F. W. T., Teng, P., Metselaar, K. (eds.) Systems Approaches for Agriculture Development, Kluwer Academic Publishers, Dordeccht.

Saseendran, S.A., Singh, K.K., Rathore, L.S., S.V. Sinha, S.K. 2000. Effects of climate change on rice production in the tropical humid climate of Kerala, India. Clim. Chan., 44: 495-514.

Sathaye, L., Shukla, P.R. and Ravindranth, N.H. 2006. Climate change, sustainable development and India: Global and national concerns. Curr. Sci., 90(3): 314-325.

Seo, S.N. and Mendelsohn, R. 2008. Climate change impacts on Latin American farmland values: the role of farm type. Revista de Econ. E. Agron., 6(2).

Sinha, S.K. and Swaminathn, M.S. 1991. Deforestation, climate change and sustainable nutrition security: a case study of India climate change, 19: 201-209.

Srinivasan, J. 2008. Climate change, greenhouse gases and aerosols. Reson., 89: 1147-1155. 
